\title{
Fate of the "opened" arterial duct: Lessons learned from bilateral pulmonary artery banding for hypoplastic left heart syndrome under the continuous infusion of prostaglandin E1
}

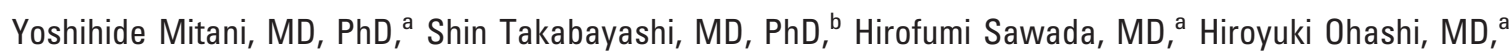
Hidetoshi Hayakawa, MD, PhD, ${ }^{a}$ Yukiko Ikeyama, MD, ${ }^{a}$ Kyoko Imanaka-Yoshida, MD, PhD, ${ }^{c}$ Kazuo Maruyama, MD, PhD, Hideto Shimpo, MD, PhD, and Yoshihiro Komada, MD, PhD, ${ }^{a}$ Tsu, Mie, Japan

Supplemental material is available online.

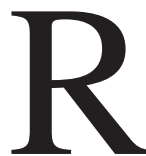
ecently, the Norwood stage I operation strategy for hypoplastic left heart syndrome (HLHS) has been challenged by proponents of the simultaneous Norwood/ Glenn procedure after stage I bilateral pulmonary artery banding (PAB) using the ductal stenting technique. ${ }^{1}$ However, the latter strategy is invasive, necessitating a hybrid approach and inherent preductal aortic coarctation. ${ }^{2}$ We recently reported a case of a patient with HLHS who successfully underwent the modified Fontan procedure after the Norwood/Glenn procedure after PAB, with the arterial duct kept open by administering lipo-prostaglandin E1 (lipo-PGE1) until the Norwood/Glenn procedure. ${ }^{3}$ We report our novel observations in the natural history of PGE1-opened arterial ducts in our series.

\section{Clinical Summary}

Five consecutive patients with HLHS underwent PAB in the neonatal period (10 \pm 2 days), followed by the Norwood/Glenn procedure at 3 to 4 months of age (121 \pm 10 days) after lipo-PGE1 infusion (3-5 ng/ $\mathrm{kg} / \mathrm{min}$ ), on the basis of the first report (case 2) ${ }^{3}$ in our series (Table 1). Serial angiograms, echocardiograms, and macroscopic and microscopic findings of the ductal tissues harvested in the operation were retrospectively investigated. During the interval between PAB and the Norwood/Glenn procedure, the ductal luminal patency was maintained in all 5 patients, as evaluated by echocardiography, angiography, and operative findings (Figures E1 and E2). However, localized intimal proliferation gradually developed at the aortic end of the duct in 4 patients

From the Departments of Pediatrics, ${ }^{\mathrm{a}}$ Thoracic Cardiovascular Surgery, Pathology, ${ }^{\mathrm{c}}$ and Anesthesiology, ${ }^{\mathrm{d}}$ Mie University Graduate School of Medicine, Tsu, Mie, Japan.

Received for publication Jan 11, 2007; accepted for publication Jan 30, 2007.

Address for reprints: Yoshihide Mitani, MD, PhD, Department of Pediatrics, Mie University Graduate School of Medicine, 2-174 Edobashi, Tsu City, Mie Prefecture, 514-8507, Japan (E-mail: ymitani@clin.medic.mie-u. ac.jp).

J Thorac Cardiovasc Surg 2007;133:1653-4

$0022-5223 / \$ 32.00$

Copyright () 2007 by The American Association for Thoracic Surgery

doi:10.1016/j.jtcvs.2007.01.053 (cases 2-5) before the Norwood/Glenn procedure, although such lesions were not obvious in 4 patients (cases 1-4) before PAB (Figures E1 and E2). The peak flow velocity at the site was minimal (1.0 and $1.1 \mathrm{~m} / \mathrm{s}$ ) in cases 1 and 2, respectively, with a minimal ridge in case 2 before the Norwood/Glenn procedure (Figure E1, $b, e$ ). A slight ridge $(2.6 \mathrm{~m} / \mathrm{s})$ developed in case 3 with no pressure gradient, as determined by catheterization before the Norwood/Glenn procedure (Figure E1, $h, i)$. A significant ridge $(3.3 \mathrm{~m} / \mathrm{s}$ ) developed in case 4, with a pressure gradient of $30 \mathrm{~mm} \mathrm{Hg}$ as determined by catheterization, at 107 days of age (Figure E2, $b, c$ ), although there was a slight ridge $(2.3 \mathrm{~m} / \mathrm{s})$, with no pressure gradient as evaluated by catheterization, at 58 days of age. Case 5 had an obvious ridge (2.1 $\mathrm{m} / \mathrm{s}$ ) even before PAB (Figure E2, $e$ ) and underwent pulmonary artery-descending aorta grafting at 33 days of age because of the significant ductal stenosis $(3.0 \mathrm{~m} / \mathrm{s})$. Ductal stenosis progressed to a pinhole lesion before the Norwood/Glenn procedure, whereas the ductal lumen was patent under lipo-PGE1 infusion (Figure E2, $f, g$ ). Macroscopic findings revealed the luminal patency of the ducts, of which circumferential ridges at the aortic sides were found in cases 4 and 5 (Figure E2, $d, h$ ). Microscopic findings showed the fibrocellular intimal lesion with the development of vaso vasorum in the ridges in cases 4 and 5 (Figure E2, $i-k$ ). The isthmus was widely open in all cases $(5.7 \pm 0.5 \mathrm{~mm})$, without any signs of retrograde preductal aortic coarctation. No obvious systemic side effects of low doses of lipo-PGE1 were found. Cases 1, 2, and 4 survived the Norwood/ Glenn procedure, among whom cases 1 and 2 completed the Fontan procedure successfully at 2 years of age, and case 4 awaits the Fontan procedure. Case 3, with associated chromosomal anomaly and intact atrial septum at the onset, and case 5, with associated multiple extracardiac anomalies, died after the Norwood/Glenn procedure because of pulmonary hypertension crisis and sudden circulatory collapse, respectively.

\section{Discussion}

The major findings in our series are two-fold: PGE1 infusion in HLHS after PAB produced an unexpectedly long duration of ductal luminal patency without preductal coarctation; however, the intimal proliferation gradually developed at the aortic end of the duct in the absence of functional closure, which unexpectedly resulted in hemodynamically significant stenosis of the duct in limited cases. Long-term ductal luminal patency during PGE1 infusion in HLHS after PAB, mimicking the environment of the duct in utero, is consistent with the increased incidence of patent ductus arteriosus in neonates with pulmonary hypertension and exaggerated vasodilator responses of the duct to PGE2 in neonatal lambs with bilateral $\mathrm{PAB} .{ }^{4}$ These findings confer the opportunity for the later second-stage Norwood operation, even with the Glenn 
TABLE 1. Clinical characteristics of patients

\begin{tabular}{|c|c|c|c|c|c|c|c|c|}
\hline \multirow[b]{2}{*}{ Case } & \multirow[b]{2}{*}{ Diagnosis } & \multirow[b]{2}{*}{ Anomaly } & \multirow[b]{2}{*}{ BBW $(\mathbf{k g})$} & \multirow[b]{2}{*}{ aAo diameter (mm) } & \multirow{2}{*}{$\frac{\text { at PAB }}{\text { Age (d) }}$} & \multicolumn{3}{|c|}{ at $N / G$} \\
\hline & & & & & & Age & BW (kg) & Isthmus diameter (mm) \\
\hline 1 & $\mathrm{AA}, \mathrm{MA}$ & & 3.5 & 2.0 & 17 & 124 & 4.7 & 5.2 \\
\hline 2 & AS, MS & & 3.4 & 5.1 & 7 & 94 & 4.4 & 4.3 \\
\hline 3 & AS, MS, IAS & Chromosome anomaly & 3.2 & 4.4 & 7 & 106 & 3.2 & 7.3 \\
\hline 4 & $\mathrm{AA}, \mathrm{MA}$ & Facial anomaly & 3.1 & 2.7 & 8 & 134 & 4.3 & 5.5 \\
\hline 5 & $\begin{array}{l}\text { AA, MS } \\
\text { VSD }\end{array}$ & $\begin{array}{l}\text { Anal atresia } \\
\text { Ear canal atresia }\end{array}$ & 3.2 & 1.9 & 12 & 149 & 4.1 & 6.2 \\
\hline
\end{tabular}

$A A$, Aortic atresia; $A S$, aortic stenosis; $M A$, mitral atresia; $M S$, mitral stenosis; $I A S$, intact atrial septum; $V S D$, ventricular septal defect; $B B W$, birth body weight; $a A o$, ascending aorta; $P A B$, pulmonary artery banding; $B W$, body weight; $N / G$, simultaneous Norwood Glenn procedure.

procedure. The localized intimal proliferation in this situation is consistent with the developmentally regulated matrix remodeling, which was previously correlated to the postnatal anatomic closure of the duct in newborn lambs. ${ }^{5}$ These findings may be a potential hazard for the long-term ductal opening in limited cases.

Collectively, the present findings may give us a biological basis and a caution for our minimally invasive strategy against HLHS, as well as a fundamental insight into the biology of the "PGE1-opened" arterial duct in humans. Further studies are warranted in this regard.

\section{References}

1. Akintuerk H, Michel-Behnke I, Valeske K, Mueller M, Thul J, Schranz $\mathrm{D}$, et al. Stenting of the arterial duct and banding of the pulmonary arteries: basis for combined Norwood stage I and II repair in hypoplastic left heart. Circulation. 2002;105:1099-103.

2. Bacha EA, Daves S, Hardin J, Abdulla RI, Anderson J, Hijazi ZM, et al. Single-ventricle palliation for high-risk neonates: the emergence of an alternative hybrid stage I strategy. J Thorac Cardiovasc Surg. 2006; 131:163-71.e2. Epub 2005 Dec 5.

3. Takabayashi S, Shimpo H, Ozu Y, Yokoyama K, Kajimoto M. A Fontan completion through stage I bilateral pulmonary artery banding for hypoplastic left heart syndrome. J Thorac Cardiovasc Surg. 2005; 130:1464-5.

4. Clyman RI, Mauray F, Heymann MA, Roman C. Influence of increased pulmonary vascular pressures on the closure of the ductus arteriosus in newborn lambs. Pediatr Res. 1989;25:136-42.

5. Rabinovitch M. Cell-extracellular matrix interactions in the ductus arteriosus and perinatal pulmonary circulation. Semin Perinatol. 1996; 20:531-41. 

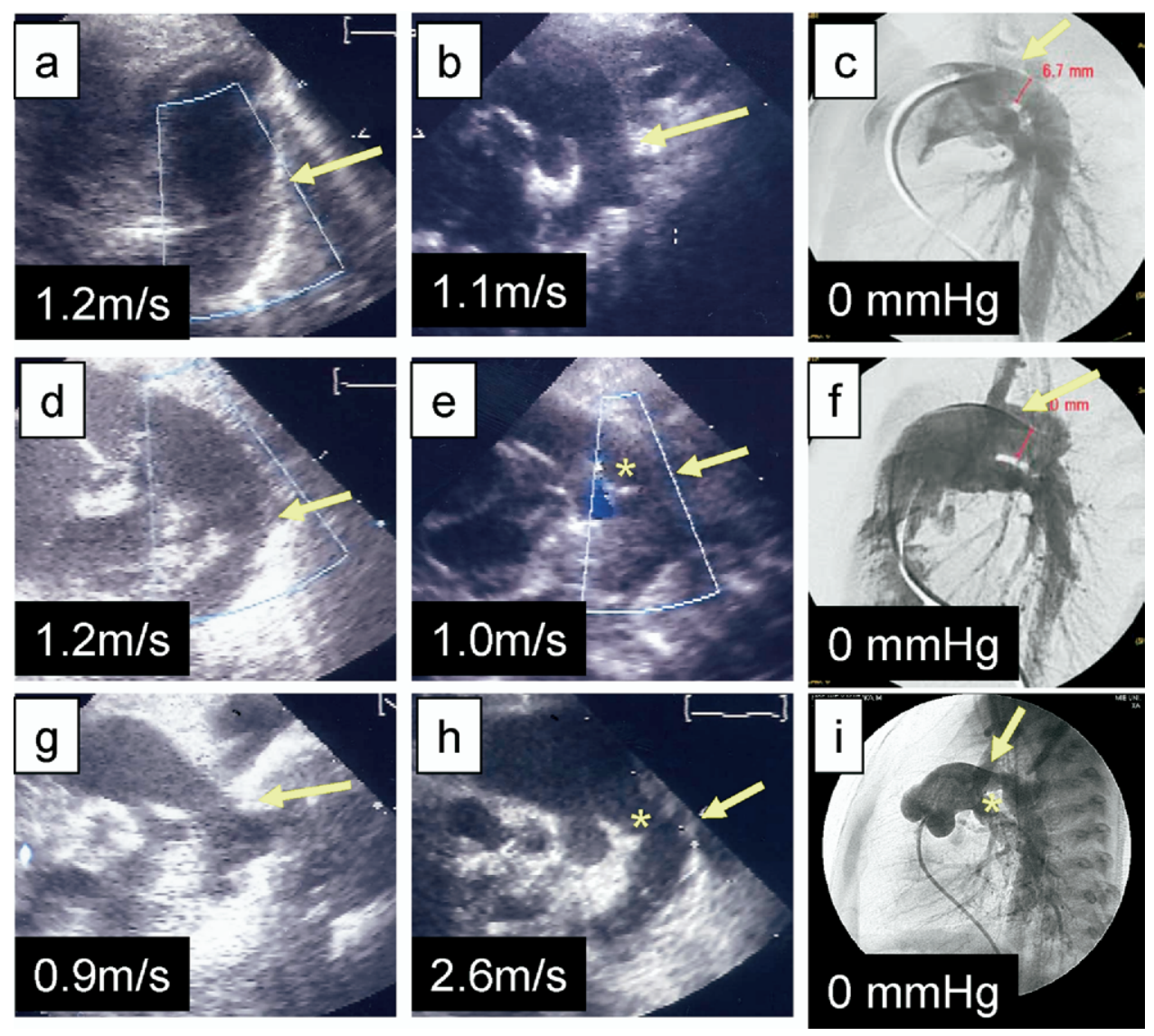

Figure E1. Echocardiograms and pulmonary angiograms in case 1 (a-c), case 2 (d-f), and case 3 (g-i). Echocardiograms delineating longitudinal sections of arterial ducts obtained before $\operatorname{PAB}(a, d, g)$ and before the simultaneous Norwood/Glenn procedure (b, e, h), before which lateral views of pulmonary angiograms were obtained (c, f, i). Continuous Doppler flow velocity in echocardiograms (left lower corner) and pressure gradient across the duct in pulmonary angiograms (left lower corner). Luminal patency of the ducts was maintained until the simultaneous Norwood/Glenn procedure in cases 1 to 3, as demonstrated by echocardiograms (b, e, h) and pulmonary angiograms (c, f, i). However, echocardiographically or angiographically obvious ridges with no pressure gradient developed at the aortic end of the ducts in cases 2 (e, f) and 3 (h, i). Arterial ducts (yellow arrows); ridges (yellow asterisk). 

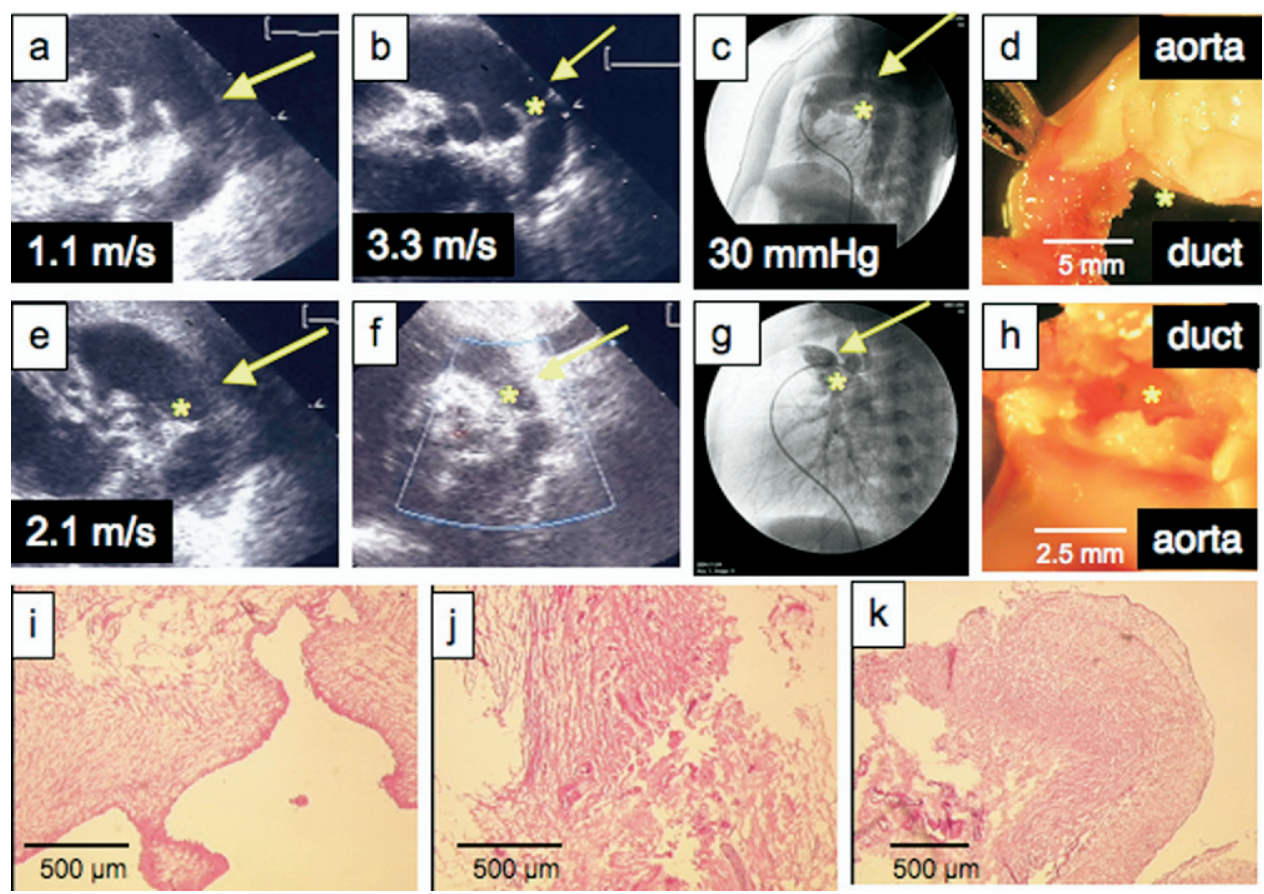

Figure E2. Echocardiograms, pulmonary angiograms, and macroscopic and microscopic findings of ductal tissues in cases 4 and 5 . Echocardiograms delineating longitudinal sections of the arterial ducts obtained before PAB (a, e) and before the simultaneous Norwood/Glenn procedure $(b, f)$, before which the lateral views of pulmonary angiograms (c, g) were obtained. Continuous Doppler flow velocity in echocardiograms (left lower corner) and pressure gradient across the duct in pulmonary angiograms (left lower corner). Macroscopic (d, h) and microscopic $(i, j, k)$ photographs were obtained from the ductal tissue harvested in the operation. Luminal patency of the duct was maintained until the simultaneous Norwood/Glenn procedure (b, c, d, f, g, h). However, an echocardiographically obvious ridge with a pressure gradient of $30 \mathrm{~mm} \mathrm{Hg}$ developed at the aortic end of the duct in case 4 (b, c, d). An echocardiographically obvious ridge with a continuous Doppler flow velocity of $2.1 \mathrm{~m} / \mathrm{s}$ was found at the aortic end of the duct even before PAB in case 5 (e). The ridge developed to a pinhole-like lesion before the simultaneous Norwood/Glenn procedure ( $f, g, h)$. Fibrocellular intimal cushion formation (i, $k$ ) with the development of vaso vasorum (j, k) was found in the macroscopic ridges (d, h). Arterial ducts (yellow arrows); ridges (yellow asterisk). 